\title{
BMJ Open Parents' perspectives on the value of assistance dogs for children with autism spectrum disorder: a cross-sectional study
}

\author{
Louise Burgoyne, ${ }^{1}$ Lisa Dowling, ${ }^{2}$ Anthony Fitzgerald, ${ }^{1}$ Micaela Connolly, ${ }^{3}$ \\ John P Browne, ${ }^{1}$ Ivan J Perry ${ }^{1}$
}

To cite: Burgoyne $L$,

Dowling L, Fitzgerald A, et al. Parents' perspectives on the value of assistance dogs for children with autism spectrum disorder: a cross-sectional study. BMJ Open 2014;4:e004786. doi:10.1136/bmjopen-2014004786

- Prepublication history and additional material is available. To view please visit the journal (http://dx.doi.org/ 10.1136/bmjopen-2014004786).

Received 6 January 2014 Revised 27 May 2014 Accepted 29 May 2014

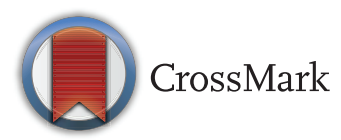

${ }^{1}$ Department of Epidemiology and Public Health, University College Cork, Cork, Ireland

${ }^{2}$ School of Medicine,

University College Cork, Cork, Ireland

${ }^{3}$ Brothers of Charity Southern Services, Cork, Ireland

Correspondence to Dr Louise Burgoyne; I.burgoyne@ucc.ie

\section{ABSTRACT}

Objective: While there is an emerging literature on the usefulness of assistance dogs for children with autism spectrum disorder (ASD), there is a dearth of quantitative data on the value of assistance dog interventions for the family unit and family functioning. Using previously validated scales and scales developed specifically for this study, we measured parents'/ guardians' perceptions of how having an assistance dog affects: (1) child safety from environmental dangers, (2) public reception of ASD and (3) levels of caregiver strain and sense of competence. We also obtained open-ended response data from parents/ guardians on benefits and constraints of having an assistance dog.

Setting: This study was based in the primary care setting, within the context of a specific accredited assistance dog centre in Ireland.

Participants: A total of 134 parents/guardians with an assistance dog, and 87 parents of children on the waiting list were surveyed.

Primary and secondary outcome measures: The primary outcome measures were scores on environmental hazards and public reception scales. The secondary outcome measures were scores on caregiver strain and competence scales.

Results: Parents/guardians of children who have ASD and an assistance dog rate their child as significantly safer from environmental dangers $(p<0.001)$, perceive that the public act more respectfully and responsibly towards their child $(p<0.001)$ and feel more competent about managing their child $(p=0.023)$ compared with parents on the waiting list. There was a concentration of positive feeling towards assistance dog interventions with particular focus on safety and comfort for children, and a sense of freedom from family restrictions associated with ASD. The amount of dedication and commitment required to care for a dog were viewed as the primary constraints.

Conclusions: Our findings indicate that parents perceive that assistance dog interventions can be a valuable intervention for families with children who have ASD.

\section{Strengths and limitations of this study}

- This study is the first to capture the views of a large group of parents/guardians on an assistance dog intervention.

- Findings suggest that parents perceive a high value in dogs for promoting safety, security and positive public reception for children with autism spectrum disorder.

- This study assessed the perceptions of parents/ guardians on the waiting list for a dog as opposed to using a stronger randomised control trial design, where controls are randomly assigned to another intervention.

\section{INTRODUCTION}

There is an expanding literature indicating the human mental and physical health benefits derived from interaction with companion animals. ${ }^{1}$ The presence of animals as an intervention tool was first studied by psychotherapist Boris Levinson ${ }^{2}$ via a series of case studies. At the time animals were seen as inferior replacements for human social interactions. ${ }^{3}$ Since the 1970s animals have been used as a means of improving human physical, emotional, cognitive and social functioning. Animal-assisted interventions (AAI) are classified into three groupings: animal-assisted activities (AAA), animal-assisted therapies (AAT) and service animal programmes (SAP). ${ }^{4}$

AAA are delivered by trained personnel in environments such as hospitals and educational settings with an emphasis on quality-of-life enhancement via recreation and education, for example, therapeutic horse riding to treat populations with physical and mental disabilities. ${ }^{5}{ }^{6}$ AAT are practiced by professionals with individualised therapy goals. ${ }^{7}$ The emphasis is on improvements in physical, social and cognitive functioning, for example, an occupational 
therapist working to facilitate fine motor skill development in a child via a series of structured tasks such as grooming and feeding a cat. A meta-analysis of the literature on AAT has shown that they are associated with moderate effect sizes in improving outcomes in four areas: autism spectrum symptoms, medical difficulties, behavioural problems and emotional well-being. ${ }^{8} \mathrm{~A}$ recent systematic review of the literature on AAI for ASD has indicated preliminary 'proof of concept', but highlights the needs for more rigorous research to establish a convincing evidence base. ${ }^{9}$ This view is upheld by another recent review pointing to the need for better research designs and larger sample sizes. ${ }^{10}$

Service animal programmes (SAP) use dogs to assist people with a disability in performing daily activities. Service dogs live inhouse with the people they work with. Of late assistance dogs have received growing attention as a means of aiding children with autism spectrum disorder (ASD). Qualitative inquiry on the integration of assistance dogs into 10 families with a child who has ASD showed that the presence of a dog can improve quality of life for children and parents. ${ }^{11}$ A study examining risks and benefits of assistance dogs using a series of structured interviews with 17 families reported social and cognitive benefits in addition to physical and medical benefits. ${ }^{12}$ An experimental study which assessed the effects of assistance dogs on basal salivary cortisol secretion of 42 children with ASD demonstrated a reduction in the cortisol-awakening response and the number of disruptive behavioural incidents postintroduction of the dog. ${ }^{13}$ Assistance dogs complete a unique triad between parent/guardian and child. Typically, the child is attached to the dog via a lead (leash) and belt. The dog walks with the child but takes commands from the parent (handler). ${ }^{14}$ If the child tries to step off a footpath or attempts to bolt, the dog will use all his/her power to slow the child down. Assistance dogs prohibit dangerous behaviour such as elopement (bolting) and provide a calming presence.

Elopement or the tendency to 'bolt' is characteristic of ASD. Such behaviour can result in a child's exposure to dangerous traffic situations or encounters with strangers. ${ }^{15}$ Despite reports of higher mortality rates in populations with ASD owing to accidents such as suffocation, drowning and injuries, research on elopement behaviour is sparse. ${ }^{16-18}$ If left untreated elopement may result in the need for a child to be moved to a restrictive setting. ${ }^{19}$ In a systematic review of the literature on current elopement treatments such as function-based interventions, Lang $e t a l^{20}$ conveyed that just 2 of 10 studies examined reported complete elimination of elopement. Treatments that effectively eliminate elopement behaviours are warranted.

Social, emotional and behavioural challenges at home and in public mean that parents/guardians of children with ASD experience stress in most areas of their lives. ${ }^{21-24}$ In addition to behaviours such as elopement, public tantrums and the reaction from others are regarded as being some of the more difficult aspects of the behaviour of a child with ASD. Situations can leave parents/guardians feeling judged as 'bad' parents, or feeling like a failure. ${ }^{25}$ In this context assistance dogs can provide a unique support by facilitating child safety and promoting positive public reception. Outings to public places can become less stressful and families can enjoy greater freedom and mobility. Given the resource implications of assistance $\operatorname{dog}$ interventions for ASD, there is a need to assess the value of acceptability and likely uptake of services.

Currently, there are 188 service animal interventions registered with the standard body Assistance Dogs International (ADI). These interventions include guide dogs for the blind, hearing dogs for the hard of hearing and service dogs for people with other disabilities including ASD. In this study we measured parents' /guardians' ratings of: (1) the impact of having an assistance dog on child safety from environmental hazards, (2) public acceptance and awareness of ASD, (3) sense of competence with managing a child with ASD and (4) levels of caregiver strain. We also obtained parents'/ guardians' views on the primary benefits and constraints of having an assistance dog.

\section{METHODS}

\section{Study design and participants}

Our study was based in the primary care setting, within the context of a specific national assistance dog intervention in the Republic of Ireland. All children who receive an assistance dog from this centre have been formally diagnosed with ASD via the Irish Health Services Executive (HSE) using standard tools such as the Autism Diagnostic Observation Schedule (ADOS), the Autism Diagnostic Interview (ADI-R) and the Diagnostic Interview for Social Communication (DISCO). Outside formal diagnosis, certain conditions such as having a child with particularly strong aggression issues may preclude participation in the assistance dog programme.

Parents/guardians with an assistance $\operatorname{dog}(\mathrm{N}=205)$ and parents/guardians on the waiting list for an assistance $\operatorname{dog}(\mathrm{N}=107)$ were eligible to take part in the study. Data were gathered between October 2012 and March 2013.

\section{Measures}

Parents/guardians were asked to complete a four-part questionnaire (table 1). Part 1 examined child demographics. Part 2 measured parents'/guardians' sense of competence for managing a child with ASD using Perceived Competence Scales $\left(\mathrm{PCS}^{26} ; \alpha=0.876\right.$, sevenpoint scales: low-high competence). The PCS is a measure of one of three fundamental psychological needs within self-determination theory. ${ }^{27}{ }^{28}$ Like other measures within behavioural change theory, items on the PCS are typically written to be specific to the relevant behaviour or domain being examined. A sample item from the PCS we used for this study is 'I am able to do my 
Table 1 Questionnaire subsections, details and measures

\begin{tabular}{|c|c|c|}
\hline Section & Details & Measure \\
\hline Part 1. Demographics & $\begin{array}{l}\text { 1. Gender, age, other medical conditions, } \\
\text { age of diagnosis, home location } \\
\text { 2. Education, learning level, verbal/non-verbal } \\
\text { Interventions and therapies received }\end{array}$ & Tick boxes, yes/no options, free text \\
\hline Part 2. Parenting and autism & $\begin{array}{l}\text { 1. Perceived competence } \\
\text { From: Self-determination theoryDeci and Ryan } 2728 \\
\text { 2. Caregiver strain questionnaire } \\
\text { From: Brannan et } a P^{9} \text { and Khanna et } a{ }^{\beta 0} \\
\text { Objective strain } \\
\text { Subjective internalised strain } \\
\text { Subjective externalised strain }\end{array}$ & $\begin{array}{l}\text { Four items on a seven-point scale } \\
21 \text { items on a five-point scale } \\
11 \text { items } \\
6 \text { items } \\
4 \text { items }\end{array}$ \\
\hline Part 3. Environment and public & $\begin{array}{l}\text { 1. Environment safety and security } \\
\text { Adapted from scale structures: Rosenberg et a/ } \\
\text { 2. Public perception }\end{array}$ & $\begin{array}{l}\text { Eight items on a seven-point scale } \\
\text { Four items on a seven-point scale }\end{array}$ \\
\hline Part 4. Benefits and constraints & $\begin{array}{l}\text { 1. Benefits of having an assistance dog } \\
\text { 2. Constraints of having an assistance dog }\end{array}$ & Free text \\
\hline
\end{tabular}

own routine caring for my child with autism'. Part 2 also assessed levels of strain using the Caregiver Strain Questionnaire $\left(\mathrm{CGSQ}^{29} ; \alpha=0.940\right.$, five-point scales: lowhigh strain), which has been validated to assess burden among caregivers of children with autism. ${ }^{30}$ The CGSQ asked participants to consider the past 6 months in terms of the problems presented by items such as: 'interruption of personal time resulting from your child's emotional or behavioural problem (objective strain)', 'How embarrassed did you feel about your child's emotional or behavioural problem? (subjective externalised strain)' and 'How worried did you feel about your child's future? (subjective internalised strain)'.

Part 3 of the questionnaire examined perceptions of child safety from environmental hazards such as traffic, dangerous materials and outdoor spaces $(\alpha=0.928$, seven-point scales: low-high safety/security). Participants were asked to rate how strongly they agreed or disagreed with respect to their child's safety and security over the past 3 months, for example, 'I am confident that my child with autism is secure from environmental hazards when we go on walks in our neighbourhood.' Part 3 also assessed parents'/guardians' ratings on the general public's acceptance of their child ( $\alpha=0.940$, seven-point scales: low-high acceptance). In this case participants were asked to rate the public's perception of their child over the past 3 months on items such as 'I am sure that people make allowances for my child with autism when we are in a restaurant'. Scales for part 3 were developed with reference to the format and structure of the Neighbourhood Environment Walkability ScaleYouth, ${ }^{31}$ and via consultation with parents and author MC, who is a psychologist specialising in children with ASD. Part 4 asked participants to list their views on the main benefits/constraints of having an assistance dog via 'free text'. Those on the waiting list were asked to give the benefits/constraints that they feel a dog will bring.

\section{Pilot}

We piloted the questionnaire with eight parents/guardians, four of whom have an assistance $\mathrm{dog}$ and four who are on the waiting list. Minor modifications were made to the final questionnaire on the basis of their responses.

\section{Procedures}

The primary caregiver from each family with an assistance dog, and each family on the waiting list received a postal questionnaire from the contact person at the assistance $\operatorname{dog}$ centre. In the interests of confidentiality, the researchers at University College Cork did not have access to names and addresses of participants. The assistance dog centre did not have access to the completed questionnaires. Each questionnaire pack contained a consent form with study details, a questionnaire, a stamped addressed envelope and an envelope marked 'Research'. Participants were requested to place completed questionnaires in the envelope marked 'Research' and to seal it. They were asked to place the sealed envelope together with the signed consent form in the stamped addressed envelope, and to post it back to the assistance dog centre. Participants were assured that participation in the study would have no impact on their status with the centre, and that staff at the centre would have no access to the survey data.

\section{Data analysis}

Descriptive statistics are reported using frequency tables. $\chi^{2}$ tests were used to test for differences between the categorical demographic variables. $t$ Tests were used to examine differences between parents of children with an assistance $\operatorname{dog}$ and those waiting to receive one, within the data on competence, caregiver strain (CGSQ), environmental hazards and public awareness. We then fitted a linear regression that included having a 
dog or being on the waiting list as a dichotomous variable and each of gender, age, home location and education as factors.

Qualitative data were analysed via open coding, followed by a process of categorisation which facilitated the emergence of themes. Author LB analysed the qualitative data initially and author LD completed a second analysis and a crosscheck.

\section{RESULTS}

\section{Demographics}

A total of 134 parents/guardians with an assistance dog (65\% response) and 87 parents/guardians from the waiting list (81\% response) completed the questionnaire. A large proportion of participants with a dog have children over the age of $10(40 \%)$ compared with just three participants from the waiting list. For this reason we eliminated the 'over tens' from further analysis in this paper.

A breakdown of the demographic characteristics of participants' children is in table 2. The majority are boys (87.5\% with dog; $91.7 \%$ waiting list) and similar percentages have other medical conditions in addition to ASD (35\% with dog; $32.1 \%$ waiting list). Other conditions include mild-to-moderate learning difficulties, attention deficit hyperactivity disorder, asthma and epilepsy. The largest group live in suburban areas $(41.3 \%$ with dog; $57 \%$ waiting list) followed by the countryside (45\% with dog; $34 \%$ waiting list). Over half of the children with a dog are verbal $(52.5 \%)$ and under half of those waiting for a dog are verbal $(42 \%)$. There are differences in types of school attended between participants whose children have an assistance dog and those who do not yet have a dog. These are reflective of the remaining age differences between the two groups postremoval of the over tens from the total sample. The main difference is that $61.3 \%$ of children with a dog attend a special school for ASD compared with $35.7 \%$ of the children on the waiting list. Conversely, $34.5 \%$ of children on the waiting list are in a special class in a mainstream primary school compared with $21.3 \%$ who have a dog.

With regard to conventional interventions received there are some descriptive differences between participants whose children have an assistance dog and those on the waiting list for a dog (table 2). There is a less than $10 \%$ difference between the groups for regular speech and language therapy $(47.5 \%$ with dog; $38.1 \%$ waiting list) and regular occupational therapy (46.3\% with dog; $38.1 \%$ waiting list). Similar percentages from both groups have a resource teacher (25\% with dog; $26.2 \%$ waiting list), and there is a $12 \%$ difference with regard to special needs assistants $(80 \%$ with dog; $67.9 \%$ waiting list).

Table 2 Participant characteristics (with $\operatorname{dog} n=80$, waiting list for $\operatorname{dog} n=84$ )

\begin{tabular}{|c|c|c|c|}
\hline Characteristics & $\begin{array}{l}\text { With dog } \\
\text { N (\%) }\end{array}$ & $\begin{array}{l}\text { Waiting list for dog } \\
\text { N (\%) }\end{array}$ & p Value \\
\hline \multicolumn{4}{|l|}{ Gender } \\
\hline Male & $70(87.5)$ & 77 (91.7) & - \\
\hline \multicolumn{4}{|l|}{ Age (years) } \\
\hline $0-6$ & $30(37.5)$ & $60(71.4)$ & \multirow[t]{2}{*}{$<0.001$} \\
\hline $7-9$ & $50(62.5)$ & $24(28.6)$ & \\
\hline \multicolumn{4}{|l|}{ Location } \\
\hline Town/city centre & $11(13.8)$ & $8(9.0)$ & \multirow[t]{3}{*}{0.217} \\
\hline Suburb & $33(41.3)$ & $47(57.0)$ & \\
\hline Countryside & $36(45.0)$ & $28(34.0)$ & \\
\hline \multicolumn{4}{|l|}{ Other conditions } \\
\hline Yes & $24(30.0)$ & $27(32.1)$ & 0.767 \\
\hline \multicolumn{4}{|l|}{ Verbal } \\
\hline Yes & $42(52.5)$ & $35(42.0)$ & 0.165 \\
\hline \multicolumn{4}{|l|}{ Education } \\
\hline Preschool & 0 & $10(11.9)$ & - \\
\hline Home tuition & $1(1.0)$ & $4(5.0)$ & - \\
\hline Primary & $13(16.3)$ & $11(31.1)$ & 0.025 \\
\hline Special class (primary) & $17(21.3)$ & $29(34.5)$ & \\
\hline Special school (ASD) & 49 (61.3) & $30(35.7)$ & \\
\hline \multicolumn{4}{|l|}{ Interventions } \\
\hline Speech and language & $38(47.5)$ & $32(38.1)$ & 0.224 \\
\hline Occupational therapy & 37 (46.3) & $32(38.1)$ & 0.290 \\
\hline Resource teacher & $20(25.0)$ & $22(26.2)$ & 0.861 \\
\hline Special needs assistant & $64(80.0)$ & 57 (67.9) & 0.077 \\
\hline
\end{tabular}


There are significant differences between profiles of children who have a dog and children waiting for a dog with respect to age and schooling. There are no significant differences between the groups for other conditions in addition to ASD, whether a child is verbal or non-verbal, conventional interventions and home location.

\section{Environmental hazards and public awareness}

The environmental hazards scales are summarised in table 3 and details of individual items are shown in online supplementary table S1. Ratings are from low perceived safety to high safety. $\mathrm{t}$ Test results showed that mean ratings are significantly higher $(p<0.001)$ for parents/guardians whose children have a dog (32.43) than for those on the waiting list (22.97). These differences remain significant after adjusting for gender, age, home location and school type $(p<0.001)$. We did however find a significant interaction between school types and whether children have a dog. Although there are significant differences between the ratings of parents/guardians with a dog and those on the waiting list for children attending a special school for autism (mean difference $=6.62: 95 \%$ CI 0.639 to 12.61 ), the effect is not as large as it is for children attending a primary school (mean difference $=12.53: 95 \%$ CI 4.16 to 20.90 ) or a special class in a primary school (mean difference $=19.4995 \%$ CI 13.171 to 25.821 ) .

The range of scores from the public perception scales (table 3 and online supplementary table S2) are from low to high, with higher scores indicating a perception of parents/guardians that people act more respectfully and responsibly towards children with ASD when in public settings. t Test results showed that parents'/guardians' mean ratings are significantly higher $(p<0.001)$ for those whose children have an assistance dog (15.87) than for those on the waiting list (10.67). For the most part these differences remain significant after adjusting for gender, age, home location and education level $(p<0.001)$. However, there was a significant interaction between type of school attended and whether children have an assistance dog. Although there are significant differences between the ratings of parents/guardians with a dog and those on the waiting list regarding where their children attend a special school for autism (mean difference $=6.65: 95 \%$ CI 3.79 to 9.51 ), and a special class in primary school (mean difference $=7.01$ : $95 \%$ CI 2.88 to 11.13 ), there is no significant difference in the ratings of parents/guardians who have a child in a mainstream primary school $(\mathrm{p}=0.09)$.

\section{Perceived competence and caregiver strain}

A summary of results from parents'/guardians' perceived competencies with regard to caring for and managing their child with ASD is shown in table 3. Details of individual items are shown in online supplementary table S3. t Test results show that mean scores for parents/guardians whose children have an assistance $\operatorname{dog}(19.75)$ are significantly higher $(p=0.02)$ in terms of perceived competencies than those on the waiting list (17.91). This difference remained significant after adjusting for gender, age, home location and education level $(p=0.02)$. Results from the CGSQ (table 3) show that parents/guardians who have a dog rated slightly lower levels of strain than those on the waiting list. However, we found no significant differences between the groups with regard to any of the individual items on the scales, or the summarised scores for 'objective strain', 'subjective internalised strain' and 'subjective externalised strain'.

\section{Benefits and constraints}

Qualitative data were analysed using a thematic approach and constant comparison techniques by authors LB and LD. Each participant's response was reviewed and codes were assigned to each 'segment of meaning'. Open codes were assigned to representative categories. The process of coding and categorisation

Table 3 Summary of results from environmental hazards, public awareness, competence and caregiver strain scales

\begin{tabular}{|c|c|c|c|c|c|}
\hline \multirow[b]{2}{*}{ Item } & \multirow[b]{2}{*}{ Description } & \multicolumn{2}{|l|}{ Mean $(95 \% \mathrm{Cl})$} & \multirow[b]{2}{*}{ Diff* $^{\star}(95 \% \mathrm{Cl})$} & \multirow[b]{2}{*}{ p Value } \\
\hline & & With dog $(n=80)$ & $\begin{array}{l}\text { Waiting for dog } \\
(n=84)\end{array}$ & & \\
\hline $\mathrm{HAZ}$ & Environmental hazards (range 8-56) & $32.43(29.47$ to 35.39$)$ & $22.97(20.83$ to 25.11$)$ & $10.9(6.97$ to 14.89$)$ & $<0.001 \dagger$ \\
\hline PUBLIC & Public acceptance(range 4-28) & $15.87(14.23$ to 17.50$)$ & $10.67(9.56$ to 11.77$)$ & 5.80 (3.69 to 7.90$)$ & $<0.001 \mp$ \\
\hline SD & Competence (range 4-28) & 19.75 (18.74 to 20.77$)$ & $17.91(16.52$ to 18.92$)$ & $1.97(0.273$ to 3.68$)$ & 0.023 \\
\hline OS & Objective strain (range 11-55) & 35.03 (32.81 to 37.20$)$ & 35.91 (34.08 to 38.01$)$ & $-0.54(-3.78$ to 2.70$)$ & 0.744 \\
\hline SIS & $\begin{array}{l}\text { Subjective internalised strain } \\
\text { (range 6-35) }\end{array}$ & 22.47 (21.21 to 23.60$)$ & 23.63 (22.89 to 25.03$)$ & $-0.81(-2.63$ to 1.00$)$ & 0.380 \\
\hline SES & $\begin{array}{l}\text { Subjective externalised strain } \\
\text { (range } 4-20 \text { ) }\end{array}$ & 7.74 (7.01 to 8.46$)$ & 7.88 (7.28 to 8.49$)$ & $-0.34(-1.37$ to 0.69$)$ & 0.522 \\
\hline
\end{tabular}


facilitated the emergence of themes from within the data. Initial qualitative analysis was performed by LB, and these results were crosschecked and refined by LD. We analysed the first and second listed benefits and constraints of having an assistance dog. Data beyond the first two benefits and constraints are sparse and not reported.

Three themes were identified under 'benefits'. These were: physical factors, relationship factors and family factors (figure 1). 'Physical factors' is divided into four categories and focuses on how assistance dogs can keep a child safe while facilitating parents' ability to manage: 'A sense of security \& protection for our daughter especially walking in local environments' (parent of girl 7-9 years old with a dog), '(Dog) will stop child from bolting from home' (parent of boy 4-6 years old on waiting list). For three of four categories, this theme is evenly dispersed between parents who have a dog and waiting-list controls. For the fourth category 'no bolt', more parents/guardians from the waiting list state the benefit of the dog being able to stop the child from eloping. 'Relationship factors' is grouped into two categories and centres on the direct positive relationship between a child with ASD and his/her assistance dog: 'She is his very best friend' ( parent of boy 4-6 years old with a dog), 'It might calm him down instead of him head banging the windows' (parent of boy 4-6 years old on waiting list). The categories making up this theme are almost evenly dispersed between parents/guardians who have a dog and waiting-list controls. 'Family factors' is split into five categories and is about how day-to-day family and social life is affected by the introduction of an assistance dog: 'Ability to do maybe ordinary things and go to ordinary places' (parent of boy 7-9 years old on waiting list), 'a sense of responsibility, for example he can feed the dog' (parent of boy 4-6 years old with a $\operatorname{dog})$. There were differences in the dispersal of this theme among parents/guardians with a dog and those on the waiting list. For example, benefits listed by those with a dog formed more of the category 'visibility', which is about public reception and awareness of ASD. Benefits listed by parents/guardians on the waiting list formed more of the categories 'social' and 'emotion and stress'. 'Social' is about the sociability of a child with ASD with family and outside the home. 'Emotion and stress' is about levels of emotion/stress in the family, and to a lesser extent the ability of the child to express emotion.

Four themes emerged from the data on constraints. These were: 'change factors', 'relationship factors', 'limiting factors' and 'no constraints' (figure 2). Change factors has three categories and focuses on lifestyle challenges that parents/guardians experience or anticipate experiencing when they have an assistance dog: "It's like an additional child in the family" (parent of boy 4-6 years old with a dog), 'To make time to go for walks everyday' (parent of boy 7-9 years old on waiting list). The categories comprising this theme are quite evenly dispersed between parents/guardians of children with a dog and those on the waiting list. Slightly more parents/ guardians waiting for a dog list 'dedication', which is the time and effort given to care for the dog as a main constraint. As with the benefits themes, 'relationship factors' is about the direct relationship between the child with ASD and the dog: "My son may not connect with the dog' (parent of boy 4-6 years old on waiting list), 'my concern is when the dog has to retire, how will my child cope?' (parent of boy 7-9 years old with a dog). More

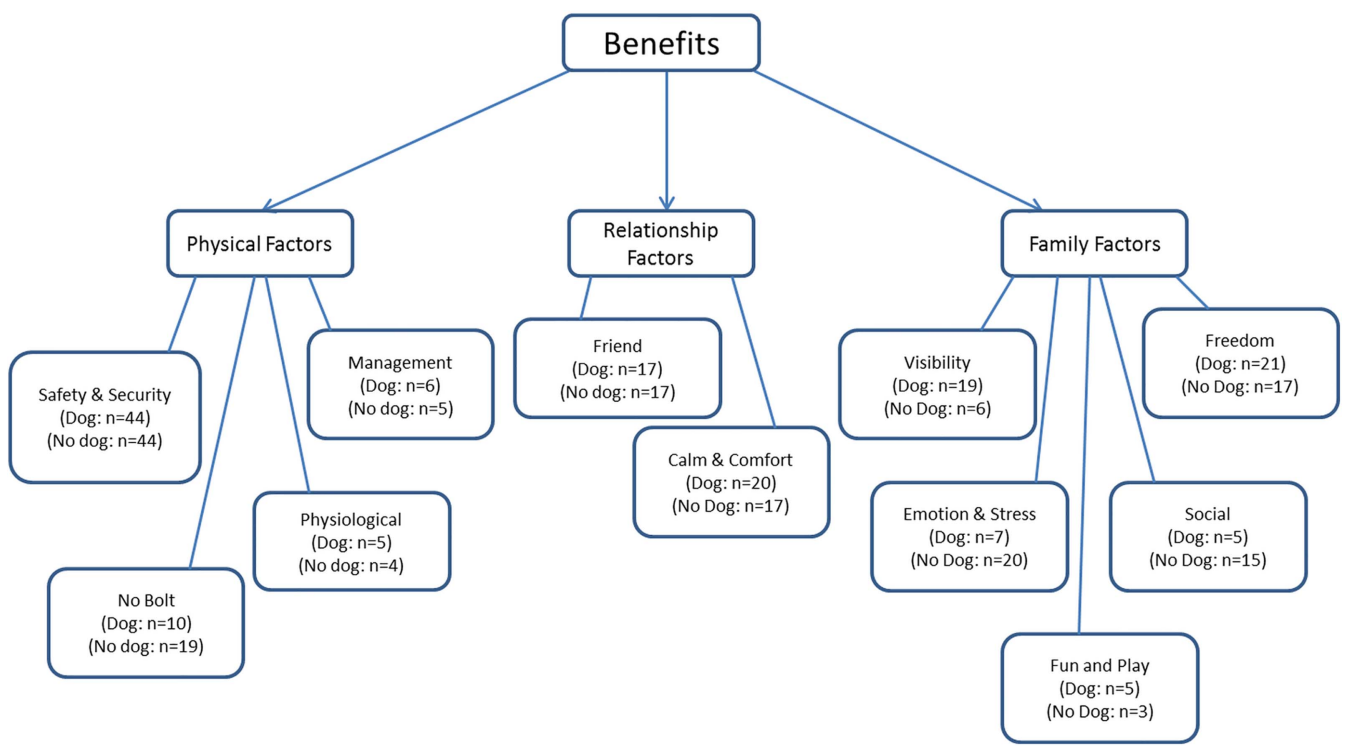

Figure 1 Parents/guardians perceived benefits of having an assistance dog (themes and categories). Ninety-nine per cent of parents/guardians with a dog listed at least two benefits. Ninety-nine per cent of parents/guardians on the waiting list for a dog listed at least two benefits. Category 'Physiological' refers to how assistance dogs can facilitate a child with respect to mobility and ambulation. Category 'management' refers to how assistance dogs can facilitate day-to-day management of their child. 


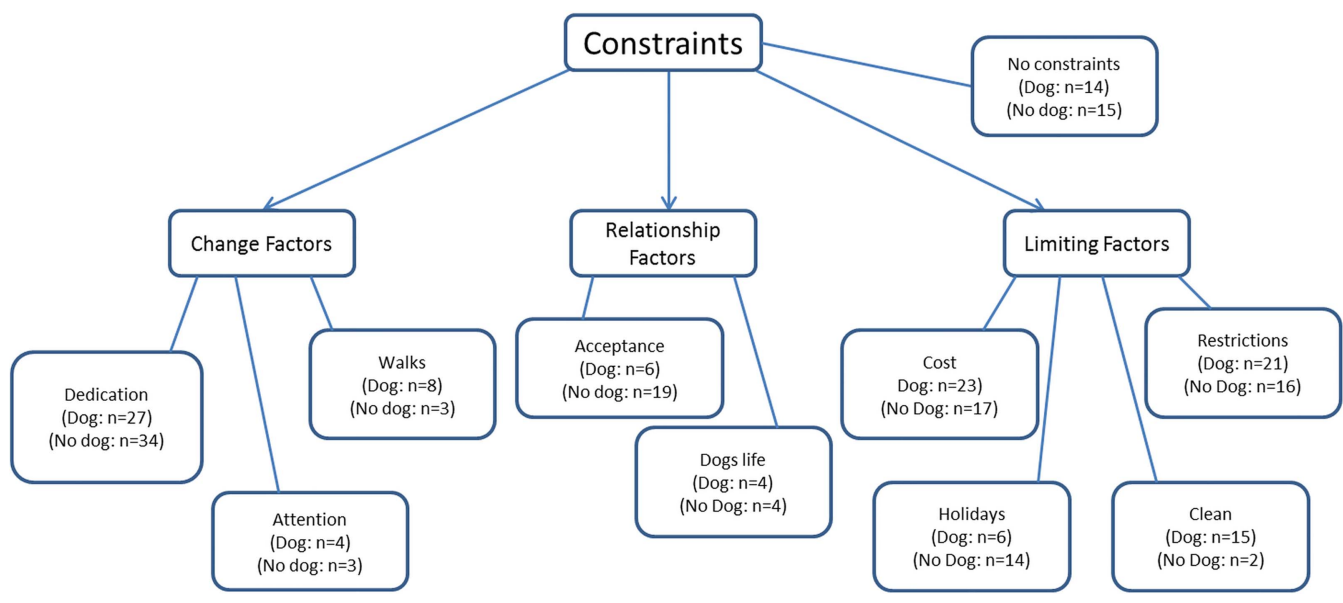

Figure 2 Parents/guardians perceived constraints of having an assistance dog (themes and categories). Sixty-six per cent of parents/guardians with a dog listed at least two constraints. Sixty-four per cent of parents/guardians on the waiting list for a dog listed at least two constraints. *Please note that one category 'other' from the waiting-list group 'second constraint' is not included in the figure. Category 'Dogs life' refers to concerns about what happens when an assistance dog retires/dies. Category 'Acceptance' refers to challenges around family and children's acceptance of an assistance dog.

parents/guardians on the waiting list make up the category 'acceptance', which is concerned about how the dog will be accepted by the child and other family members. The third theme 'limiting factors' has four associated categories and centres on day-to-day constraints of having a dog on family life; 'Extra expense for food, vet bills etc' (parent of boy 7-9 years old with a dog), 'it will be a bit difficult to travel' (parent of boy 4-6 years old on waiting list). There are large differences in the dispersal of two of the categories within this theme. In particular, more parents/guardians whose children have a dog contributed to the category 'clean', which is about day-to-day hygiene activities related to the dog, for example, dog hair in the house and dealing with dog toileting. More parents/guardians on the waiting list contributed to a category on 'holidays', which expressed concerns about going on holidays with the dog. The final theme 'no constraints' has just one category. This was a category in which parents/guardians stated no issues for concern or anticipated drawbacks; 'There are none....our dog is a valuable and much loved addition to the family' (parent of boy 7-9 years old with a dog), 'don't anticipate any, feeling very positive about it' (parent of boy 4-6 years old on waiting list). This category was almost evenly dispersed between parents whose children have a dog and those on the waiting list.

\section{DISCUSSION}

Our study is the first to capture the views of a large group of parents/guardians on an assistance dog intervention. Quantitative findings indicate the value of dogs in promoting safety, security and positive public reception for children with ASD. They also suggest that the presence of an assistance dog may make parents/guardians feel more competent with managing their child. Qualitative findings indicate the role assistance dogs play in promoting child safety, calmness and provision of friendship. They also highlight the role the dog has in facilitating 'normal' family functioning, such as being able to visit a shopping centre. Constraints associated with having a dog relate to specific lifestyle changes experienced by parents/guardians and the larger family group, such as dedicated care of the dog.

There are several study limitations. First, our findings are based on self-reports and parents'/guardians' personal perceptions and are thus subject to participant overestimation, recall bias and possible subject expectancy effects. Also since we did not include any objective measures, we cannot know whether parents' perceptions reflect reality, for example, were children actually safer and did the public actually view them more positively when accompanied by an assistance dog. Second, there were differences in children's ages and type of schools attended between our two sample groups which resulted in removal of the over tens from our analyses and a reduction in sample size. Third, we did not assess the views of parents/guardians who are not registered with the assistance dog centre. Our results therefore can only be relevant to parents who are open to the possibility of having an assistance dog. A fourth limitation of the study is that we assessed the perceptions of waiting-list controls as opposed to using a randomised control trial design, where controls are randomly assigned to another intervention. Ideally we would employ a planned activity, another animal such as a cat or a robotic dog as a control. Such a design was not feasible however and the current data do provide insights.

Recognition of the role animal interventions play in promoting human health is gaining momentum. Animal interventions have been shown to produce increases in self-efficacy and coping in patients with psychiatric conditions, ${ }^{32} 33$ promoting recovery from ill health $^{3} 34 \quad 35$ and improving academic performance, 
adaptive functioning and behavioural/emotional problems in adolescents receiving special education. ${ }^{36}$ ASD is one of the areas within which animal interventions have had most success. ${ }^{8}$ This is particularly the case for assistance dog interventions, since dogs provide a possible mechanism for promoting improvements in social and behavioural functioning, and also play a part in control of elopement and promotion of child safety. Once a child is attached to a dog via the leash and belt system they cannot 'bolt'. In this study parents/guardians with a dog rated their child as considerably more safe from environmental hazards than did waiting-list controls. We did find a reportable interaction between having an assistance dog, type of school attended and parents'/guardians' ratings. This interaction indicated a lesser albeit significant effect of having a dog for parents/guardians whose children attend a special school for ASD. The smaller effect may be due to the specific care that children and families receive from ASD schools. Currently, there are no interventions that can successfully eliminate elopement among children with ASD. ${ }^{20}$ Our quantitative findings support the role of assistance dogs in providing this service. Our qualitative findings provide additional validation with safety and security being the most frequently stated benefit of having a dog.

Behavioural, social and emotional difficulties that encompass the lives of children with ASD can impact parents'/guardians' well-being. ${ }^{21}{ }^{22}$ Our findings suggest that assistance dogs can provide parents/guardians with a higher sense of competency with regard to managing their child than waiting-list controls. This result may reflect added support dogs provide in public settings. Indeed, public tantrums and reactions from the public are regarded as one of the more difficult aspects of the behaviour of a child with ASD. ${ }^{25}$ Qualitative results from this study highlight the role that an assistance dog has in promoting public awareness and acceptance of ASD. Quantitative results suggest that parents/guardians whose children have assistance dogs rate the public's perception of their child as more positive. Our regression analysis did show an interaction between having an assistance dog and type of school attended. On examination we found that while the ratings of parents/guardians remained significantly different regarding where their children attend a special school for autism or a special class in primary school, they were not significantly so where children attend a mainstream primary school. Such a result may reflect a lack of awareness/ acceptance of ASD in mainstream schools.

Our findings from the CSGQ show no significant differences between parents/guardians who have a child with a $\mathrm{dog}$, and those waiting to receive a dog. There are three subscales within the CGSQ. 'Objective strain' deals with the caregiver burden of day-to-day tasks related to care, 'subjective internalised strain' deals with negative feelings internal to the caregiver and 'subjective externalised strain' deals with negative feelings of the caregiver towards the child. We considered two reasons which may explain the lack of any real differences between the groups with regard to caregiver strain. First, it is known that being a parent/guardian of a child with ASD can affect quality of life with respect to levels of care and support required, and the resulting impacts on family finance and family time. ${ }^{37} 38$ In our study parents/guardians expressed that the dedication required to care for a dog is a main constraint. Assistance dogs require feeding, exercise, affection, grooming, regular company and financial expenditure. The added task of looking after an assistance dog may not therefore impact positively on levels of caregiver strain. Second, we noticed that our sample scores on the CSGQ were generally less positive than scores from parents/guardians who took part in the most recent CSGQ validation study. ${ }^{30}$ This may reflect a lower provision of services for families of children with autism in the Republic of Ireland. It is interesting to note that although there were no significant differences between parents/guardians who have a dog and those on the waiting list for a dog with respect to caregiver strain, there were significant differences with respect to perceived competence. Why do parents/guardians with a dog feel more competent but no less strained? A possible explanation is that the process and actual event of getting an assistance dog, and the specific procedures followed with respect to working with the dog may make parents/ guardians feel more competent. Having a dog may add more structure to parents' management technique without necessarily reducing levels of strain associated with having a child with ASD.

The ability of assistance dogs to provide a sense of calm and comfort to children with ASD is documented. ${ }^{11} 13$ Qualitative results from this study lend support to this view. Parents/guardians with an assistance dog frequently mentioned the dog's ability to promote calmness in their child. Those on the waiting list anticipated ways in which the dog would aid their child in times of distress. Previous research has recognised the role that dogs have in facilitating social development in children with ASD. ${ }^{12} 36{ }^{39}$ Our qualitative findings point to the idea that assistance dogs can act as a 'bridge' between children and the physical and social environment. However, more parents/guardians on the waiting list for a dog wrote about the anticipated ability of a dog to promote social development in their children than those with a dog. Those with a dog wrote more about the increased public awareness and acceptance of their child as the main benefit. It may be that although parents waiting for a dog to anticipate changes in social interaction, this does not emerge as the most important benefit once they actually get a dog. That assistance dogs may facilitate social interaction in children with ASD is not in dispute. However, this role may be more salient in AAT, where a trained therapist may work with a dog to reach specific cognitive or behavioural goals for a child. Parents' /guardians' listed constraints of having an assistance dog were centred on the lifestyle changes. 
Such changes include the care and costs required to ensure a dog's health and well-being in addition to the restrictions associated with the dog's requirements for exercise and companionship. It is important to recognise that each parent/guardian has a different level of tolerance for specific canine behaviours. ${ }^{40}$ While many of the parents/guardians in our study discounted the constraints of having a dog, some were explicit about their concerns. More of those with an assistance dog expressed concern about the increase in housekeeping tasks, and specific hygiene activities associated with having a dog in the family home. Parents/guardians with children on the waiting list were more concerned about whether the dog will be accepted by the child and family, and logistics during family holiday time. Our results suggest that some of the anticipated constraints do not necessarily emerge as the most important constraints once a dog is placed in the home. Differences in expectations highlight the importance of working with families to best understand their needs and concerns before and after obtaining an assistance dog.

\section{CONCLUSIONS}

Our findings indicate that parents/guardians perceive assistance dog interventions are valuable in the treatment of ASD, particularly in relation to the control of elopement. They also perceive that assistance dogs help to promote calmness and provide a source of comfort for children.

Contributors LB was the lead researcher and was involved in the design, implementation, analysis and reporting of the study. LD took part of the project as her final year medical project. She was involved in the qualitative analysis and interpretation together with the overall reporting of the study and approval of the manuscript. $A F(T)$ is the study statistician responsible for interpretation of the quantitative data and final approval of the manuscript. MC is a psychologist specializing in children with autism. She was involved in the study design and was the clinical adviser to the group throughout the course of research. She was also involved in the study reporting and approval of the manuscript. JB is a psychologist and health services researcher. He was involved in the study analysis, critical review and approval of the manuscript. IJP was the main project supervisor. He was responsible for overseeing the project from start to finish and approved the final manuscript.

Funding This research received no specific grant from any funding agency in the public, commercial or not-for-profit sectors.

Competing interests None.

Ethics approval Clinical Research Ethics Committee of the Cork Teaching Hospitals.

Provenance and peer review Not commissioned; externally peer reviewed.

Data sharing statement Technical appendix, statistical code and dataset available from the corresponding author at University College Cork, who will provide a permanent home for the dataset.

Open Access This is an Open Access article distributed in accordance with the Creative Commons Attribution Non Commercial (CC BY-NC 3.0) license, which permits others to distribute, remix, adapt, build upon this work noncommercially, and license their derivative works on different terms, provided the original work is properly cited and the use is non-commercial. See: http:// creativecommons.org/licenses/by-nc/3.0/

\section{REFERENCES}

1. O'Haire M. Companion animals and human health: benefits, challenges and the road ahead. J Vet Behav 2010;5:226-34.

2. Levinson BM. Pet-oriented child psychotherapy. Spingfield, IL: Charles C Thomas, 1969.

3. Endenburg N, van Lith HA. The influence of animals on the development of children. Vet $J$ 2011;190:208-14.

4. Lasa SM, Ferriero G, Brigatti E, et al. Animal-assisted interventions in internal and rehabilitation medicine: a review of the recent literature. Panminerva Med 2011;53:129-36.

5. Bass MM, Duchowny CA, Llabre MM. The effect of therapeutic horseback riding on social functioning in children with autism. J Autism Dev Disord 2009;39:1261-7.

6. Kern JK, Fletcher CL, Garver CR, et al. Prospective trial of equine-assisted activities in autism spectrum disorder. Altern Ther Health Med 2011;17:14-20.

7. Parish-Plass N. Animal assisted therapy with children suffering from insecure attachment due to abuse and neglect: a method to lower the risk of intergenerational transmission of abuse? Clin Child Psychol Psychiatry 2008;13:23.

8. Nimer BLJ. Animal assisted therapy: a meta analysis. Anthrozoos 2007;20:13.

9. O'Haire ME. Animal-assisted intervention for autism spectrum disorder: a systematic literature review. J Autism Dev Dis 2013;43:1606-22.

10. Berry A, Borgi M, Francia N, et al. Use of assistance and therapy dogs for children with autism spectrum disorders: a critical review of the current evidence. J Altern Complement Med 2013;19:73-80.

11. Burrows KE, Adams CL, Spiers J. Sentinels of safety: service dogs ensure safety and enhance freedom and well-being for families with autistic children. Qual Health Res 2008;18:1642-9.

12. Davis BW, Nattrass K, O'Brien S, et al. Assistance dog placement in the pediatric population: benefits, risks, and recommendations for future application. Anthrozoos 2004;17:130-45.

13. Viau R, Arsenault-Lapierre G, Fecteau S, et al. Effect of service dogs on salivary cortisol secretion in autistic children. Psychoneuroendocrinology 2010;35:1187-93.

14. Burrows KE, Adams CL, Millman ST. Factors affecting behavior and welfare of service dogs for children with autism spectrum disorder. J Appl Anim Welf Sci 2008;11:42-62.

15. Piazza CC, Hanley GP, Bowman LG, et al. Functional analysis and treatment of elopement. J Appl Behav Anal 1997; 30:653-72.

16. Shavelle RM, Strauss DJ, Pickett J. Causes of death in autism J Autism Dev Disord 2001;31:569-76.

17. Mcllwain L, Fournier W. Wandering and autism: the need for data and resources. National Autism Association, 2010. http://iacc.hhs. gov/events/2010/slides_fournier_mcilwain_102210.pdf

18. Anderson C, Law JK, Daniels A, et al. Occurrence and family impact of elopement in children with autism spectrum disorders. Pediatrics 2012;130:870-7.

19. Perrin C. Brief functional analysis and treatment of elopement in preschoolers with autism. Behav Intervent 2008;23:8.

20. Lang R, Rispoli M, Machalicek W, et al. Treatment of elopement in individuals with developmental disabilities: a systematic review. Res Dev Disabil 2009;30:670-81.

21. Firth I, Dryer R. The predictors of distress in parents of children with autism spectrum disorder. J Intellect Dev Disabil 2013;38:163-71.

22. Seymour M, Wood C, Giallo R, et al. Fatigue, stress and coping in mothers of children with an autism spectrum disorder. Autism Dev Disord 2013;43:1547-54.

23. de Andrés-García S, Sariñana-González P, Romero-Martínez A, et al. Cortisol response to stress in caregivers of offspring with autism spectrum disorder is associated with care recipient characteristics. Stress 2013;16:510-19.

24. Hayes SA, Watson SL. The impact of parenting stress: a meta-analysis of studies comparing the experience of parenting stress in parents of children with and without autism spectrum disorder. J Autism Dev Disord 2013:43:629-42.

25. Ludlow A, Skelly C, Rohleder P. Challenges faced by parents of children diagnosed with autism spectrum disorder. $J$ Health Psychol 2012;17:702-11.

26. Williams GC, Freedman ZR, Deci EL. Supporting autonomy to motivate glucose control in patients with diabetes. Diabetes Care 1998;21:1644-51.

27. Deci EL, Ryan RM. Intrinsic motivation and self-determination in human behavior. New York: Plenum, 1985.

28. Deci EL, Ryan RM. The "what" and the "why" of goal pursuits: human needs and the self-determination of behavior. Psychol Inq 2000;11:27-268. 
29. Brannan AM, Heflinger CA, Bickman L. The caregiver strain questionnaire: measuring the impact on the family of living with a child with serious emotional problems. J Emotional Behav Disord 1997:5:212-22.

30. Khanna R, Madhavan S, Smith MJ, et al. Pyschometric properties of the Cargiver Strain Quesionnaire (CGSQ) among caregivers of children with autism. Autism 2011;16:179-99.

31. Rosenberg D, Ding D, Sallis JF, et al. Neighborhood Environment Walkability Scale for Youth (NEWS-Y): reliability and relationship with physical activity. Prev Med 2009;49:213-18.

32. Berget B, Ekeberg O, Braastad B. Animal assisted therapy with farm animals for persons with psychiatric disorders: effects on self efficacy, coping ability and quality of life, a randomised controlled trial. Clin Pract Epidemiol Ment Health 2008;4:9.

33. Bizub AL, Joy A, Davidson L. "It's like being in another world": demonstrating the benefits of therapeutic horseback riding for individuals with psychiatric disability. Psychiatr Rehabil J 2003;26:377-84.

34. Friedmann E, Thomas SA. Pet ownership, social support, and one year survival after acute myocardial infarction in the cardiac arrhythmia suppression trial (CAST). Am J Cardiol 1995;76:1213-17.

35. Morrison ML. Health benefits of animal-assisted interventions. Complement Health Pract Rev 2007;12:51-62.

36. Katcher AH, Teumer SP. A four year trial of animal assisted therapy with public school special education students. Handbook on animal assisted therapy: theoretical foundations and guidelines. Aubrey fine. 2nd edn. San Diego: Academic Press, 2006.

37. Jarbrink $\mathrm{K}$. The economic consequences of autistic spectrum disorder among children in a Swedish municipality. Autism 2008;11:453-63.

38. Cassidy A, McConkey R, Truesdale-Kennedy M, et al. Preschoolers with autism spectrum disorders: the impact on families and the supports available to them. Early Child Dev Care 2008;178:115-28.

39. Solomon $\mathrm{O}$. What a dog can do: children with autism and therapy dogs in social interaction. J Soc Psychol Anthropol 2010;38:1:143-66.

40. Sanders CR. Excusing tactics: social responses to the public misbehaviour of companion animals. Anthrozoos 2004:4:82-90. 